\title{
LEGADO MULTIDISCIPLINAR DE FRANCISCO CLEMENTINO DE SAN TIAGO DANTAS
}

\author{
Fábio Maria De-Mattia \\ Professor Titular do Departamento de Direito Civil da \\ Faculdade de Direito da Universidade de São Paulo
}

A escolha do legado jurídico de San Tiago Dantas para tema de aula inaugural deste ano letivo no curso noturno se justifica para os acadêmicos de Direito familiarizarem-se com a importância da vida e obra de um dos brasileiros mais proeminentes deste século.

Por outro lado, esta Academia, que ele conheceu e respeitou, não poderia se manter silente quando da passagem do trigésimo ano de seu passamento. Seguindo o exemplo de outras instituições nacionais como a Escola de Advocacia da Seção do Estado do Rio de Janeiro da OAB que, em outubro de 1994, dedicou uma sessão solene para evocar sua fulgurante passagem pelo mundo do Direito e pela vida pública, prestamos, nesta Revista, nossas homenagens a este ilustre professor.

A justificativa completa-se dado o cinqüentenário da aula inaugural dos cursos da Faculdade Nacional de Direito, ministrada por San Tiago Dantas, sob o título "A educação jurídica e a crise brasileira" que, até hoje, é um referencial quando se discute o currículo no ensino do Direito.

Inicialmente abordaremos aspectos biográficos de San Tiago Dantas e o desdobramento de suas atividades como professor, advogado, empresário, consultor influente de governos e em seguida sua passagem marcante e histórica pela vida política e administrativa no exercício dos cargos de deputado federal, ministro de Estado das Relações Exteriores e da Fazenda, com desempenho comprovado, passados mais de trinta anos, de quem atuou visualizando décadas além de seu tempo e, finalmente, nos deteremos na sua importante e diversificada produção jurídica quer em decorrência da atividade no magistério quer como monografista, parecerista, autor de artigos jurídicos e como causídico.

* Esta homenagem foi realizada em aula inaugural ministrada, em 1995, no curso noturno da Faculdade de Direito, relativa ao trigésimo ano da morte de Francisco Clementino de San Tiago Dantas. A Comissāo de Publicação entendeu publicá-la, neste fascículo, no ano comemorativo dos 500 Anos do País, relembrando, nas palavras do Autor, o grande mestre jurídico. 
Pode ser inserido na categoria rarissimamente alcançada de jurisconsulto.

Trata-se de um dos vultos mais eminentes do Brasil no campo da cultura, dotado de uma das inteligências mais agudas e objetivas de nosso tempo. Foi considerado, por muitos, a figura mais importante de sua geração.

Quem comprova sua condição de primus inter pares? São os luminares mais representativos de nossa cultura, enumerando alguns deles: Afonso Arinos de Mello Franco. Alceu Amoroso Lima, Augusto Frederico Schmidt, Gilson Amado, José Honório Rodrigues, Marcílio Marques Moreira, Otávio de Faria, Plínio Salgado e Roberto de Oliveira Campos.

Humanista versado em literatura, história, filosofia, sociologia e nas artes em geral; jurisconsulto, cuja presença se faz sentir na atualização e renovação do Direito Civil pátrio, no dizer de Arnoldo Wald; mestre de Direito, lúcido e atualizadíssimo; orador fluente, límpido e persuasivo; primoroso homem de letras; diplomata e estadista; parlamentar que nos faz lembrar pela sua contribuição intelectual e como formulador de soluções, os grandes de Minas: David Campista, Carlos Peixoto, Pandiá Calógeras; financista professor de Economia Política na Faculdade de Arquitetura e na Escola Superior de Guerra.

Era um polimorfo sem superficialidades, luminoso sem eclipses, acadêmico e, contudo, operacional, capaz de rigor da ciência e da singeleza das artes, como foi analisado detidamente.

San Tiago Dantas ingressa na Faculdade de Direito aos dezesseis anos, quando já se familiarizara com autores da envergadura de Goethe, Kant, Nietzche, Bergson, Rimbaud e Baudelaire.

Encontrando entre seus colegas um grupo de grande valor intelectual, organiza com eles o "Caju" Centro de Estudos Jurídicos e Sociais, entidade política de idéias e de cultura que exerceu profunda influência em sua geração.

Quais eram os seus colegas do Caju? Álvaro Penafiel, Américo Jacobina Lacombe, Antonio Galloti, Aroldo de Azevedo, Gilson Amado, Hélio Viana, Otávio de Faria, Plínio Doyle, Thiers Martins Moreira, Vicente Constantino Chermont de Miranda e Vinicius de Morais.

Segundo o escritor Otávio de Faria: "Não havia entre os seus membros a mais leve discrepância sobre dois pontos: a lúcida rejeição de qualquer ideologia de base marxista e a mais absoluta admiração pela inteligência de San Tiago Dantas" 
Aos dezenove anos ei-lo brindando nossas letras com um trabalho sobre Joaquim Nabuco. A respeito dele, diz Plínio Salgado: Percebi pela forma, estilo e maneira de tratar a matéria, que êle, como Nabuco, filiava-se à corrente estilistica e à de pensamento de Renan e dos racionalistas franceses do século passado. Realmente, Joaquim Nabuco foi, entre nós, aquele que exprimiu o sentido linear, o equilibrio perfeito do estilo literário e, até mesmo, de atitude pessoal daquele grupo francês que era, na ocasião, a pura expressão do espírito filosófico"

Afonso Arinos de Mello Franco situa a atuação literária de San Tiago Dantas: "e como ele, Jorge Amado, Schmidt e Hamilton Nogueira, entre outros, foram, para mim, a revelação de que a literatura brasileira deixava de ser, somente estética e se transformava em espelho de crítica social de afirmação ideológica: de esquerda, de direita ou reformista cristã" (Prefácio a 'Dom Quixote, um apólogo da Alma Ocidental" $2^{\mathrm{a}}$ ed., Rio, Editora Tempo Brasileiro, 1964, p. XIII).

É evidente que, nesta époєa, não poderia ter escapado ao espírito de San Tiago Dantas a convivência com Proust. A admiração pela obra do escritor russo o leva à constituição da Sociedade dos Amigos de Proust.

Quando já se preparava para nos deixar, quis visitar os lugares que aparecem na obra de um dos seus autores preferidos. Esta viagem nos é relatada, magistralmente, pelo ministro Marcílio Marques Moreira, amigo dileto do mestre, colaborador e presença constante nos últimos anos que relata e reflete: "Quer visitar Illiers, o Combray da infância de Proust. Diante da igreja do vilarejo, entre romântica e gótica, da casa de tia Léonie e de Françoise, no Jardim 'du côte de chez Swann, era o reencontro do tempo perdido. Lembrado do adiantado da hora, responde ser esta a última oportunidade de conhecer, diretamente, o que só conhecia, embora tão de perto, através da leitura de um dos seus autores preferidos. Pergunta pelas aubépines, mas já haviam murchado. Em vida não teria a oportunidade de ver as aubépines florir, como, também, não lhe seria dado ver desabrochar muitas outras flores, que cultivara com tanto zelo. A irremediabilidade do Tempo foi um tema constante de reflexão. Era o que o fascinava em Bergson e Proust, ambos voltados para o mistério do fluir do Tempo, e também em Baudelaire, cujos versos sabia de cor. 'O douleur, o douleur, le temps mange la vie'"

Antes de se bacharelar em Direito, colaborou no jornal " $A$ Razão" onde deixou importante contribuição. Foi um dos fundadores e redatores.

Ingressou na Faculdade Nacional de Direito da então Universidade do Brasil, em 1928, concluindo o curso em 1932. 
No relato de Alberto Venâncio Filho o professor San Tiago Dantas "entre os mestres guardou lembranças muito nítidas de Abelardo Lobo, Afonso Celso, Virgílio de Sá Pereira e Lacerda de Almeida" ("San Tiago Dantas e o Ensino Jurídico" em "San Tiago Dantas Um Seminário na Universidade de Brasília" Brasília, Editora Universidade de Brasília, 1985, p. 50).

Lecionou na que viria a ser a Faculdade de Arquitetura da Universidade do Brasil, na época Escola Nacional de Belas Artes, segundo depoimento de Américo Jacobina Lacombe onde, quase adolescente e recémformado, ocupou, pela porta larga do concurso, a cadeira de Legislação de Construções" Inicia-se, também, no magistério de Economia Política e Finanças. $\mathrm{O}$ interesse pelos temas econômicos revela-se já quando estudante, como comprova no artigo publicado sobre "A situação do comércio mundial da prata"

Em 1939 é aprovado em concurso para professor catedrático de Direito Civil na Faculdade de Direito da Universidade do Brasil sucedendo na cátedra a Virgílio de Sá Pereira. Em 1940 passa a ensinar na Escola de Estado Maior do Exército como professor e conferencista de Economia Política. Em 1941 assume a direção da Faculdade Nacional de Filosofia, permanecendo até 1945 sendo, de fato, o organizador da referida instituição.

Fundada a Faculdade de Direito da Pontifícia Universidade Católica do Rio de Janeiro assume a regência da cadeira de Direito Romano. Em 1946 leciona em Faculdade de Direito da Universidade de Paris. Em 1951 foi conselheiro da Delegação Brasileira à Quarta Reunião de Consulta dos Chanceleres americanos, em Washington, EUA.

A partir de 1952 torna-se membro do Comitê Permanente de Arbitragem de Haia. Em 1953 atua como chefe de Delegação Brasileira na $3^{a}$ Reunião da Comissão Interamericana de Jurisconsultos, realizada em Buenos Aires, Argentina. Em 1955 é eleito presidente na reunião da Comissão Interamericana de Jurisconsultos, o que se estendeu até 1958.

É eleito deputado federal pelo Estado de Minas Gerais, em 1958, e reeleito, em 1962, pelo PTB - Partido Trabalhista Brasileiro. Em 1960 cria o projeto que resultou na Lei n. 3.752 de 14 de março, criando o Estado da Guanabara. Em 22 de agosto de 1961 é nomeado pelo presidente Jânio Quadros para exercer as funções de embaixador junto à Organização das Nações Unidas ONU não tendo assumido o posto. Com o advento do regime parlamentarista assume, em setembro de 1961, o Ministério das Relações Exteriores. 
Em janeiro de 1962 chefia a Delegação Brasileira na $8^{\mathbf{a}}$ Reunião de Consulta dos ministros das Relações Exteriores, em Punta del Este, Uruguai e no mesmo semestre participa da Conferência de Desarmamento, em Genebra, Suíça, quando seu desempenho teve grande repercussão; quanto à segunda, sua atuação ensejou manchetes nos principais jornais europeus.

Deixa o Ministério das Relações Exteriores em 25 de junho de 1962, para se candidatar à reeleição como deputado federal obtendo êxito.

Em julho de 1962 é indicado pelo presidente João Goulart para o exercício das funções de primeiro-ministro mas não consegue ter seu nome aprovado pelo Congresso Nacional.

Dias atrás expus ponto de vista sobre a tragédia nacional que foi a rejeição de seu nome para o exercício das funções de primeiro-ministro a um dos mais eminentes cientistas políticos e sociólogos do País e estávamos plenamente sintonizados de que foi a grande oportunidade para a instauração do regime parlamentar de Governo, mas a recusa foi o início do processo de deterioração política, econômica e social que se encerrou com a quebra da ordem institucional em março de 1964.

A desaprovação de sua indicação resultou de episódio gerado pela incompetência política tanto da direita quanto da esquerda.

O próprio presidente da República convocou um deputado federal, seu correligionário e licenciado para exercer uma das mais importantes embaixadas na Europa, com o intuito de que regressasse ao País para auxiliar nas articulações políticas para a aprovação do primeiro-ministro indicado, mas, alguns dias depois de intensa atividade política, o deputado-embaixador é chamado ao Palácio para ouvir do presidente que cessasse qualquer articulação. Portanto, traído nas suas bases político-partidárias.

Preocupado com a sinalização da quebra constitucional e decidido a levar a frente o projeto de governo que combatesse a inflação e executasse reformas, nos faz lembrar o que hoje se pretende proceder no País. Assume, em janeiro de 1963, o cargo de ministro da Fazenda para exercê-lo por pouco mais de cinco meses, revelando-se o competente estudioso e professor de Economia Política e Ciência das Finanças, assuntos que ensinara na Faculdade de Arquitetura da então Universidade do Brasil e na Escola Superior de Guerra.

Obtém êxito internacional com sua Missão San Tiago Dantas aos EUA. É recebido pelo presidente John Kennedy para entrevista que excedeu o 
horário protocolar, o que foi objeto de comentários pela imprensa internacional.

Regressa com a saúde abalada e encontra partidários do que cognominou a esquerda negativa desestabilizando o Governo, o que o convence, com alguns ministros, a optar pela demissão.

De junho de 1963 a $1^{\circ}$ de abril de 1964 foi o grande articulador de seu último projeto político: unir as forças responsáveis e lúcidas da Nação em torno de um pacto nacional que salvasse o Governo daquilo que o esperava: a deposição.

O ministro Marcílio Marques Moreira, seu importante colaborador, amigo, presença constante em seus últimos anos, descreveu de maneira precisa e sábia o que significava a figura de San Tiago Dantas para o País: "Como em tantas Iutas em que se empenhou, San Tiago não veria, entretanto, florir a árvore, tenra e nobre, que então cultivava. Homem do futuro, importava-lhe mais plantar uma semente do que uma flor. A esse desprendimento que soube destilar de forma cada vez mais pura à medida que pressentia a hora de despedir-se de seu percurso terreno San Tiago aliava espantosa familiaridade com a complexa tessitura em que se entrelaçavam moral e direito, política e economia, sociedade e cultura, ciência e tecnologia; passado, presente e futuro; política interna e realidade mundial. Era a invulgar capacidade de que dispunha San Tiago para pensar e agir, para antever e advertir, para formular e sugerir, com grandeza e presciência, que Ihe conferia a verdadeira dimensão de estadista" ("San Tiago Dantas, O Estadista" em "San Tiago Dantas Um seminário na Universidade de Brasília" Editora Universidade de Brasília, 1985, p. 47).

Após a tentativa de apresentar aos acadêmicos uma visão da vida construtiva e diversificada de San Tiago Dantas, passemos à análise de seu legado jurídico.

Comecemos por alguns aspectos de sua produção científica a respeito do ensino, em particular do Direito.

Alguns de seus mais importantes trabalhos vinculados à vida acadêmica, ao ensino do Direito, estão reunidos em livro sob o título "Palavras de um Professor" (1 $1^{\mathrm{a}}$ ed., Rio, Forense, 1975), título escolhido pelo próprio mestre.

O historiador Américo Jacobina Lacombe, amigo por toda a vida do mestre San Tiago Dantas, na orelha do livro esclarece: "Esta coleção é, assim, um pequeno espelho da ação magistral de San Tiago Dantas. O seu título, por ele mesmo escolhido, indica o rumo de uma carreira desviada de seu curso pela vocação política em que se consumiu na derradeira fase da curta e luminosa 
trajetória"

O volume inicia-se com o discurso proferido a 30 de agosto de 1940 , ao tomar posse na cátedra de Direito Civil da Faculdade Nacional de Direito da Universidade do Brasil.

Analisa o Direito Civil como o campo das aquisições lentas, das transformações aluvionais. Lidando com grandezas microscópicas, penetrando nos alvéolos sociais, analisando e perquirindo os tecidos, decompondo as células, o trabalho do civilista não atinge a forma geral, mas atinge a substância, fixa os detalhes da sociedade" (ob. cit., p. 18). Focaliza: "Nele se hão de reunir e combinar dois elementos sem os quais será falseado o seu trabalho; o espírito conservador do sistema e a docilidade às normas jurídicas. $O$ espírito conservador é talvez a essência do espírito civilistico, e se exprime naquela tendência que os jurisconsultos romanos levaram à perfeição, de ligar o novo ao antigo, de conquistar para o moderno os brasões do passado, só reconhecendo no sistema uma alteração, quando os seus quadros são inflexíveis à recepção do fato novo. O segundo elemento a docilidade às normas é o que dá vida e autenticidade ao trabalho do jurista, e impede que o seu ensinamento recaia sobre um sistema hipotético, diferente na verdade do que rege as relações humanas na vida real" (ob. cit., p. 19).

O espírito aberto ao progresso do Direito o leva à reflexão sobre a "Renovação do Direito" por ocasião do cinqüentenário da Faculdade de Direito da então Universidade do Brasil. Em 1945 dirige-se aos novos bacharéis abordando "Novos Rumos do Direito" Em 1957, dirigindo-se aos novos bacharéis, enfrenta o tema "Em defesa do Direito" Em aula proferida no curso sobre humanismo, organizado pela Pontifícia Universidade Católica do Rio de Janeiro, em 1948, discorre sobre "Humanismo e Direito"

Ao assumir a diretoria da Faculdade Nacional de Filosofia da então Universidade do Brasil, em 1941, discursa sobre "Os Estudos filosóficos e a sua significação no mundo moderno"

Um quarto de século após, profere a aula inaugural na mesma Faculdade que instalara e dirigira e, na antevéspera de 31 de março de 1964, versa o tema da "Reforma Universitária" no quadro das transformações institucionais, de que necessita o País para substituir suas antigas estruturas por outras, capazes de atender às aspirações da nova sociedade. Enfoca a reforma universitária analisando 0 quadro nacional. Aponta dez diretrizes que, explica, "são esses os princípios, ou antes os traços característicos, que podem, a meu ver situar, nos dias de hoje, uma 
reforma universitária na linha da transformação social, que se vem cumprindo em nosso País, sem liderança cultural definida, com enorme vitalidade, mas com retardamentos desnecessários e desperdícios evitáveis" ("Palavras de um Professor" p. 198).

Apontava, igualmente, nesta aula inaugural, para uma preocupação que foi objeto de suas últimas manifestações: o risco do neosubdesenvolvimento: " $O$ risco do neosubdesenvolvimento ainda é maior do que o do subdesenvolvimento, de que ainda não logramos sair. $O$ distanciamento relativo entre os povos detentores da ciência e da tecnologia modernas e os povos não detentores pode relegar estes últimos à condição de uma subumanidade"

Este tema foi objeto, no mesmo mês, de palestra na Associação Comercial de São Paulo que, acredito, tenha sido sua última visita a São Paulo.

O trabalho mais significativo deste aspecto na preocupação de San Tiago Dantas com a nossa atividade universitária reside num tema que, continuamente, é um desafio e que se intitula "A educação jurídica e a crise brasileira" que foi objeto da aula inaugural dos cursos da Faculdade Nacional de Direito, em 1955. Neste trabalho apresenta um esboço de reforma do curso e dos currículos.

A importância deste estudo motivou uma dissertação de mestrado sob o título "Introdução ao idealismo jurídico" (Uma releitura da aula magna de San Tiago Dantas: A Educação Jurídica e a Crise Brasileira"), do professor da Faculdade de Direito da Universidade Federal de Santa Catarina, Edmundo Lima De Arruda Junior (Julex Livros, Campinas, $1^{\mathrm{a}}$ ed., 1988).

"A Educação Jurídica e a Crise Brasileira" se compõe dos seguintes capitulos: "Sociedade e Cultura; Progresso, Decadência e Cultura; Classe Dirigente e Cultura; Decadência Cultural e Secessão Política; A crise da Sociedade brasileira e a universidade; A Cultura Jurídica e a Crise Social; Restauração da Cultura Jurídica pela Educação; A didática tradicional e a nova didática; 'Text System versus case system;; Conseqüência da nova didática; Críticas ao ensino casuístico; Formação geral versus formação especializada; Técnica de currículo flexível; Os currículos especializados; O velho criticismo; Vivificações da educação Jurídica; Resumo e Conclusão"

Em seguida apresenta esboço de reforma quando prevê quatro especializações: a. Direito Penal; b. Direito Administrativo; c. Direito Comercial e d. Economia e Ciências Sociais. 
Ao cuidar das cadeiras na parte dedicada ao esboço de Reforma, na seção III desta parte de seu trabalho, sob o número 4 propõe: "Os professores de disciplinas que se ensinam em mais de um ano lecionarão em cada série rotativamente, de modo que a mesma turma de alunos conserve, para cada disciplina, ao longo do curso, o mesmo professor" ("Palavras de um Professor" ob. cit., p. 101).

A proposta prevê na seção I sob o número 3: "Cada um dos currículos, embora desenvolvendo predominantemente o estudo de uma especialidade, contém as disciplinas necessárias à formação jurídica total, e confere diploma de bacharel em Direito, com idêntica capacitação" ("Palavras de um Professor" $1^{\text {a }}$ ed., Rio, Forense, p. 97).

O item IV do "Esboço de Reforma" prevê, no número 1: "O ensino das disciplinas será ministrado em aulas de preleção e sessões de trabalho, realizadas na própria Faculdade, ou em cursos externos, realizados em outras escolas superiores, quando a disciplina não foi lecionada em cadeira da Faculdade". (ob. cit., p. 102).

Já o número 3 prevê: As sessões de trabalho constarão de estudos, investigações, debates, análise de casos forenses ou de problemas e exercícios escolares, com a participação ativa dos alunos e a assistência ou orientação do professor, e terão a duração máxima de três horas, não se podendo realizar mais de uma sessão num só dia" (ob. cit., p. 102).

Quanto à atuação de San Tiago Dantas na Escola Superior de Guerra noticia o ministro Marcílio Marques Moreira: "Outrossim, muitas de suas conferências que pronunciou entre 1951 e 1962, na Escola Superior de Guerra, versaram sobre politica exterior, inclusive duas proferidas, em 1953, e que haveriam de alcançar grande influência no pensamento da própria Escola, em que analisou o Poder Nacional do ângulo da técnica das relações exteriores do Estado e em relação aos objetivos permanentes e às grandes aspirações nacionais" ("San Tiago Dantas Um Seminário na Universidade de Brasília" Editora da Universidade de Brasília, 1985, p. 45).

Ainda quanto à ligação de San Tiago Dantas com a Universidade cabe transcrever o relato, de Américo Jacobina Lacombe, a respeito do discurso proferido na Universidade de Cracóvia, Polônia, ao receber, em 1962, o título de doutor honoris causa: "proferido em francês, quase de improviso, e cujos ecos ainda pude recolher, quando ali passei meses depois. Suas graves palavras levou-as o vento. 
Mas guardou-as como um encantamento a lembrança de professores que me transmitiram ainda a vibração do espanto com o que viram elevar-se a tão grandes altitudes"

Passemos agora à análise da produção científica de San Tiago Dantas constituída de monografia de concurso, volume de pareceres, textos sobre Política Exterior e Relações Internacionais, coletânea primorosa e fundamental sobre alguns dos grandes vultos do Direito nacional, pareceres não-publicados em livro e memoriais.

O professor Francisco Clementino De San Tiago Dantas é autor de obra dedicada ao estudo do conflito de vizinhança que pode ser qualificada como o momento alto alcançado no estudo da matéria. A avaliação é concretizada tendo presente a bibliografia internacional.

Trata-se de trabalho elaborado para a conquista da cátedra de Direito Civil na então Faculdade de Direito da Universidade do Brasil, hoje Faculdade de Direito da Universidade Federal do Rio de Janeiro.

Pode-se afirmar que aquele concurso marca uma fase de transição no Direito Civil brasileiro: sua monografia é um ponto de referência para uma tese estruturada cientificamente, afastada do modelo de trabalho meramente exegético como ocorria no Brasil e ainda muitas vezes no Exterior.

Ousaria afirmar ser a bibliografia de Direito Civil nacional textomodelo do civilista que já pensava e escrevia tendo conviç̧ão de que as fronteiras entre o Direito Público e o Direito Privado não mais existiam de modo a não se inserir as disciplinas de um ou outro ramo do Direito em compartimentos estanques.

Basta citar que na primeira parte da monografia encontramos três capítulos: um dedicado ao conflito de vizinhança em seus lineamentos gerais, o segundo dedicado ao estudo das normas administrativas sobre a vizinhança industrial e o terceiro ao exame do conflito de vizinhança no Direito Privado.

A segunda parte da monografia, também constituída por três capítulos, desenvolve o estudo dos atos emulativos e o abuso do direito em um capítulo; 0 seguinte concerne às teorias sobre a vizinhança quando se detém em dois aspectos centrais antes de prosseguir: o fundamento da responsabilidade e a lesão do direito.

$\mathrm{Na}$ terceira parte sistematiza as teorias sobre a vizinhança tendo como ponto central o critério da tolerabilidade e intolerabilidade das imissões, o que o leva a traçar os lineamentos das teorias da imissão corpórea, do uso normal e da necessidade. 
San Tiago Dantas convence ser imperioso de se gizar um critério doutrinário, o que faz optando por critério de necessidade, atendendo simultaneamente a dois princípios: a necessidade geral de cada proprietário e a necessidade geral do povo numa visão onde o público e o privado não poderiam estar dissociados.

A leitura de um texto escrito há quase sessenta anos impressiona pelo distanciamento em relação a outros trabalhos. Nessa época a construção doutrinária deixava a desejar pela opção por uma das correntes em voga, mas todas insuficientes pela sua limitação como também pela falta de operacionalidade.

Após optar por um misto da teoria do uso normal, cuja elaboração mais moderna vinha de Ihering, e o critério da necessidade de Bonfante, San Tiago Dantas conclui que se impunha conceber novo critério doutrinário.

San Tiago Dantas assentou as linhas definitivas das formas de composição do conflito de vizinhanças, contribuição invocada pelos autores de estudos sobre a matéria e pela jurisprudência. Baseiam-se nas lições do mestre: Orlando Gomes, Caio Mário da Silva Pereira, Sílvio Rodrigues, Arnoldo Wald, Maria Helena Diniz, Marco Aurélio Silva Viana, entre outros.

Em capítulo dedicado aos deveres e direitos de vizinhança cuida com relevante contribuição de: a relação de vizinhança como relação jurídica, dever jurídico e direito subjetivo de vizinhança: análise do art. 554 do Código Civil.

A qualificação dos deveres de vizinhança como relações jurídicas e situações jurídicas propter rem e a natureza real dos direitos de vizinhança foram objeto das reflexões do grande mestre.

Examina a indenização nos direitos de vizinhança, e a dupla origem destes: a coexistência dos direitos e a supremacia do interesse público. Além disso, dedica-se, também, a análise dos princípios gerais do tema.

Finaliza o importante trabalho estruturando o critério sistemático de composição do conflito entre vizinhos, quando defende a necessidade de um duplo critério de composição do conflito de vizinhança, calcado na destinação do imóvel.

Nesta linha de construção defende a aplicação do princípio da coexistência dos direitos, abordando o tradicional critério da normalidade e também a aplicação do princípio da supremacia do interesse público com a aplicação do critério da necessidade.

O saudoso mestre, no item 137 da clássica monografia, tendo presente o art. 554 do Código Civil, concebe os três modos através dos quais o juiz pode 
compor um conflito dessa espécie:

"10 Verificando que os incômodos são normais, e que não o seria privar o interferente da livre prática dos atos reclamados, o juiz mandará tolerar os incômodos, atuando o direito de vizinhança, gratuitamente concedido a todos os proprietários, de terem as suas imissões toleradas pelos proprietários dos prédios vizinhos;

$2^{\circ}$ Verificando, porém, que os incômodos são excessivos por ser anormal o uso da propriedade que lhes dá origem, o juiz indagará se a supremacia do interesse público legitima este uso excepcional; se legitima, e se a ofensa à saúde, segurança ou sossego não é de molde a inutilizar o imóvel prejudicado, o juiz manterá os incômodos inevitáveis e, pela expropriação que assim inflige ao proprietário incomodado, ordenará que se lhe faça cabal indenização (direito oneroso de vizinhança);

$3^{\circ}$ Se, porém, o interesse público não legitima o uso excepcional, é de 'mau uso' que se trata, e o juiz mandará cessar" (Francisco Clementino De San Tiago Dantas, " $O$ conflito de vizinhança e sua composição" $2^{\mathrm{a}}$ ed., texto definitivo, de acordo com observações e notas deixadas pelo autor, Rio, Forense, 1972, pp. 280 e 281).

Na lição de Arnoldo Wald vigora em nosso País a conciliação formulada por San Tiago Dantas, a qual além do uso normal, admite o uso anormal socialmente necessário ("Curso de Direito Civil Brasileiro Direito das Coisas" $2^{\mathrm{a}}$ ed. revista e atualizada, São Paulo, Sugestões Literárias SA, 1970, pp. 178 e 179).

San Tiago Dantas focaliza a adoção do critério do uso normal em nosso Direito nos seguintes termos: "Dentre os vários critérios suscitados para dar conteúdo definitivo ao 'mau uso' de que fala o Código, nenhum logrou maior sucesso na jurisprudência que o do 'uso normal' (...). Esse critério, seja qual for o seu valor teórico, tem sobretudo por si dois argumentos práticos, que sempre o recomendarão à confiança dos juizes" (ob. cit., p. 315).

E indica: "O primeiro é a larguíssima parte que nele se faz às sugestões da eqüidade (...). O segundo é a liberdade que o critério em causa deixa ao magistrado, de fazer a Justiça do caso, sem perder de vista a tutela de certos interesses comuns e as razões da utilidade social. .... Assim, a normalidade se decide sempre por aproximação, e quem julga desta é o critério íntimo do juiz" (ob. cit., p. 316).

San Tiago Dantas, sem procurar fundir as teorias de Ihering e 
Bonfante, em verdade, ao elaborar suas regras de composição de conflito, leva ambas em consideração.

Estaria ele concordando com as idéias preconizadas por ambas as teorias? Ou procurou atualizar a de Ihering com as críticas de Bonfante? Na verdade, não se manifesta sobre o problema, apenas nos cabe formular deduções.

Talvez se possa concluir que a teoria do uso normal na composição dos conflitos de vizinhança, como se apresenta em nossa jurisprudência, é a formulação resultante do pensamento jurídico de San Tiago Dantas, que a racionalizou ao inserir os princípios da coexistência dos direitos e da supremacia do interesse público.

Ensina San Tiago Dantas que o magistrado, diante do conflito submetido ao seu julgamento, tem três soluções para, eventualmente, oferecer às partes: $1^{\circ}$ mandar tolerar as interferências verificadas; $2^{\circ}$. mandá-las cessar; $3^{\circ}$. mandá-las tolerar, obrigando, porém, o proprietário interferente a pagar ao interferido uma indenização.

A contribuição de San Tiago Dantas pela sua importância se faz sentir na jurisprudência nacional, onde se tornou uma constante a referência ao critério por ele formulado constituído de regras para solucionar o conflito. Não-bastava apenas saber se o uso era normal ou anormal, ou como interpretar as expressões do art. 554 do Código Civil dentro deste contexto. Era necessário formular regras que resolvessem, dentro do critério da eqüidade, os conflitos de vizinhança.

A monografia ora examinada de San Tiago Dantas representa um fortalecimento da prevalecente teoria do uso normal, comprovando que não interessa o estudo acadêmico de teorias sem ter em vista sua praticidade, a sabedoria no resolver os problemas que as invocam. Estas exigências encontram seu melhor campo de trabalho justamente na teoria do uso normal.

A importância de "O conflito de vizinhança e sua composição" comprova-se atualmente quando se verifica na notável monografia sobre "Uso Nocivo da Propriedade" de autoria de Vilson Rodrigues Alves (São Paulo, Editora Revista dos Tribunais, 1992), existir num exame rápido pelo menos quarenta citações.

A idéia de se atualizar a monografia " $O$ conflito de vizinhança e sua composição" foi do notável professor titular Rubens Limongi França que lera o trabalho na preparação do concurso para obter o título de livre docente e que sugeriu obtermos a autorização para tal intento. No segundo semestre de 1963 apresentamos 
ao mestre San Tiago Dantas a proposta, que foi aceita de pronto, pois seria executada pelo professor Limongi França com minha colaboração de recémformado.

Em janeiro de 1964 iniciamos a execução do trabalho, sabedores que tínhamos de ser rápidos pois o estado de saúde do mestre se deteriorava e desejávamos entregar-lhe o trabalho a tempo. Em abril de 1964 foi-lhe entregue o "esboço para a atualização da obra" trabalho elaborado pelo professor Rubens Limongi França que recebeu total aprovação e, na oportunidade, foi relatado 0 estágio dos trabalhos. A entrega dos originais da atualização ocorreu a 15 de agosto de 1964. Com o falecimento do professor San Tiago Dantas, a viúva autorizou e se encarregou de cuidar da publicação da obra, atualizada pelo professor Thiers Martins Moreira e, anos após, com o seu falecimento, o dr. Plínio Doyle assumiu tal intento. Em 1972, a $2^{\mathrm{a}}$ edição veio a lume. É de Justiça relembrar o empenho e dedicação do saudoso Antonio Gontijo De Carvalho no sentido de que a decisão de San Tiago Dantas fosse respeitada e cumprida. Coube-lhe, por decisão familiar e dos amigos próximos à família, prefaciar a segunda edição.

Em abril de 1964 o saudoso professor, por ocasião da elaboração das notas para a sua ainda hoje obra clássica, porém sempre atual, recomendou-me livro que sabia importante mas que não pudera consultar e forneceu-me de memória 0 nome do autor: Paul Leyat e da obra: La responsabilité dans les rapports de voisinage" (Librairie du Recueil Sirey, Paris, 1936).

Após obter exemplar no Exterior cheguei a preparar duas notas para a reedição de "O conflito de vizinhança e sua composição" contudo as mesmas não foram inseridas.

Há trabalho escrito na década de quarenta, quando foi publicado na Revista Forense e, em 1953, inserido em "problemas de Direito Positivo" que, pela importância da temática, comprova que San Tiago Dantas acompanhava, atualizado, os assuntos jurídicos focalizados pelos especialistas do primeiro mundo.

Trata-se de "Evolução contemporânea do direito contratual" certamente, até quinze anos, atrás um texto moderno. Apresenta-se como de citação obrigatória para quem tem cuidado da matéria entre nós, como tenho comprovado.

Aborda tipos de normas até então não-correntes entre nós; ali assinala o mestre: "Outras normas, menos numerosas, parecem, entretanto, pôr em xeque, de maneira mais direta, as concepções básicas da doutrina dos contratos. São elas, sobretudo, as que não se limitam a fixar total ou parcialmente o conteúdo dos 
contratos, mas chegam a criar a obrigação de contratar, atingindo assim o princípio da autonomia, não-só na sua primeira manifestação, que é a liberdade contratual, mas também na segunda, que é a liberdade de contrair ou não uma obrigação. As leis que obrigam a vender, aplicáveis em regra a produtores $e$ fornecedores de gêneros alimentícios ou de matérias-primas; as que obrigam a produzir, aplicáveis a indústrias, cujos estabelecimentos são solicitados pelo Poder Público a aceitar e executar determinadas encomendas; as que obrigam a comprar, aplicáveis sobretudo nas subscrições compulsórias de empréstimos públicos, dão lugar a contratos coativos, em que a autonomia da vontade se reduz a um simples ato de obediência, para evitar a imposição de sanções legais" (p. 22).

E conclui: " $O$ exame das características e problemas do direito dos contratos, no momento atual, conduz às seguintes conclusões: 1) a multiplicação das formas de contratos, na prática contemporânea dos negócios, prova a vitalidade do principio da autonomia da vontade, malgrado as múltiplas manifestações do interesse publico, que se traduzem em limitações e regras coercitivas; 2) o principio da obrigatoriedade das convenções de direito público e privado deve sofrer as restrições necessárias para que as obrigações tornadas excessivamente onerosas em conseqüência de atos governamentais ou de modificações sociais consideráveis e inesperadas sofram uma revisão a pedido da parte interessada, dentro de limites estabelecidos em lei; 3) é desejável que um sistema de sançôes eficazes seja estabelecido para dar uma força obrigatória mais efetiva aos contratos concluídos entre empresas pertencentes ou controladas pelo Estado, ou com organismos internacionais" (ob. cit., p. 33).

Consta que a introdução de noção de empresa pública no Direito brasileiro se deve a San Tiago Dantas, na qualidade de conselheiro do presidente Getúlio Vargas.

San Tiago Dantas pôde marcar sua presença também como conhecedor de Direito de Autor. Parecer versando sobre "divulgação clandestina de obra literária pela radiofonia" inserido em "problemas de Direito Positivo" mas datando de uma década antes, é um marco significativo de um texto de Direito de Autor que se afastou do que se escrevia, entre nós, distante em algumas décadas do estágio da literatura especializada na Itália e em França, naquele principalmente.

Cuida da adaptação do texto "Floradas da Serra" de Dinah Silveira de Queiroz, para irradiação na forma de peça teatral por uma das rádio-emissoras de São Paulo, sem autorização e aparecendo como sendo original de outrem. Tratava-se 
de plágio que ensejou ação cível contra a emissora, o autor do plágio e o radiofonizador.

San Tiago Dantas escolhe justamente para paradigma da solução dada ao caso concreto o jusautoralista reconhecido como o maior especialista italiano da primeira metade do século: Piola Caselli.

Mas a dificuldade centrou-se em como estipular a indenização. San Tiago Dantas, com criatividade, porque não-invoca nenhum autor ou precedente jurisprudencial, concebe um critério.

Tal solução consistiu no seguinte: aplicar a regra do hoje revogado art. 669 do Código Civil, que o mestre utiliza através da seguinte construção: Devemos, então, pensar no critério sugerido pelo art. 669 do Código Civil, onde a indenização, em vez de ser baseada no ganho do violador, é calculada sobre o prejuizo do proprietário lesado. Ora, este vinha, no caso em exame, divulgando sua obra através de livros postos à venda, e foi a esta venda que a rádio-emissora fez ilegítima concorrência, lançando ao público, em irradiações sucessivas, o inteiro teor daquele romance. Não falseamos, antes transpomos harmoniosamente a vontade da lei, se equiparamos essa irradiação a uma edição clandestina, derramada em certa área do País. Cada recepção integral da peça Eterna Esperança correspondeu a um exemplar clandestino da obra plagiada posta em circulação. Notemos que a lei manda apreender ou indenizar cada exemplar editado, e não cada exemplar lido. Daí decorre que não importa averiguar quantos aparelhos receptores efetivamente captaram a irradiação da peça, é fácil precisar, dada a área de penetração da emissora o número de aparelhos existentes nessa área. Notemos ainda que a lei manda satisfazer o proprietário com a entrega dos exemplares apreendidos ou do valor da edição, calculado ao preço dos exemplares genuínos. Equiparando a irradiação a uma edição clandestina, não podemos ter a esperança de apreendê-la, mas, se sabemos quantas audições foram possíveis, e se conhecemos o valor de mercado de cada exemplar genuíno, podemos com facilidade alcançar o valor pelo qual a 'edição radiofônica' será indenizada" (pp. 415 e 416).

E conclui seu parecer tão-criativo: "Também não impressiona a consideração do vulto atribuído à 'edição radiofônica, estimada em tantos exemplares quanto os aparelhos receptores existentes na área de penetração da emissora. A divulgação pelo rádio também excede imensamente a divulgação do livro. E, portanto, o dano sofrido pelo autor com a radiodifusão de sua obra é incomparavelmente maior que o resultante da derrama de exemplares clandestinos. 
Se é verdade que um livro serve a vários leitores, também é certo que um aparelho receptor proporciona a irradiação a vários ouvintes simultaneamente. E, assim, em tudo vai coincidindo o paralelo entre a edição e a irradiação"

Ainda: "Pode ser, porém objetado que o fato de irradiarem simultaneamente várias estações, torna praticamente fictícia aquela possibilidade de ser ouvido o mesmo programa por todos os aparelhos ao alcance da emissora em questão. Nesse caso, apenas teríamos de procurar nos dados estatísticos existentes ou de confiar ao prudente arbítrio do juiz a fixação de um coeficiente adequado para por ele estimarmos a participação daquela emissora no que poderiamos denominar o mercado da radiodifusão" (ob. cit., p. 416).

San Tiago Dantas é um exemplo do jurista interdisciplinar como o que ainda temos hoje na figura do jurisconsulto e filósofo Miguel Reale.

Basta a análise dos temas desenvolvidos em vários setores do Direito como o comprova a leitura de "problemas de Direito Positivo"

O estudo sobre "Igualdade perante a lei e due process of law" é freqüentemente citado em trabalhos sobre o assunto e consta de "problemas de Direito Positivo" (pp. 35 a 64).

Neste livro há um ensaio sobre "Terras Devolutas na Faixa de Fronteiras Direito de quem as adquiriu do Estado à expedição de título definitivo pela União" (pp. 108 a 126), tema clássico de Direito Agrário de natureza publicista.

Em "problemas de direito positivo" encontramos estudos de Direito Administrativo, Direito Econômico, Teoria Geral do Direito, Direito Internacional Privado, Direito Civil, Direito Comercial e Direito Processual.

Entre os últimos trabalhos forenses publicados podem ser indicados: 1. "Regime legal de separação" 1951; 2. "Homologação de Sentença Arbitral" 1952; 3. "Honorários por serviços prestados em Juizo Arbitral" 1954; 4. "Creação de município por Lei Estadual" 1954; 5. Em defesa da Constituição do Estado do Rio Grande do Sul' 1954; 6. Desempate de indicações em concurso de catedrático" 1955; 7. Renovação de aluguel por arbitramento" 1958; entre outros.

Tive conhecimento que o mestre San Tiago Dantas manteve relações profissionais com o jurisconsulto e professor Tullio Ascarelli que, como professor visitante da Faculdade de Direito da Universidade de São Paulo, exerceu influência junto aos estudiosos de Direito, entre eles alguns futuros professores desta Academia, inclusive comercialistas e tributaristas. 
Ouvira tal informação de meu professor de Direito Romano, Thomas Marky, que por razões profissionais conhecera San Tiago Dantas em assunto a que estava ligado o grande jurista Tullio Ascarelli.

Com efeito há parecer em processo de que San Tiago Dantas e seu caro colega e amigo Plinio Doyle foram os advogados.

Trata-se de demanda referente à homologação de sentença arbitral, sendo certo que, por ocasião da apresentação de memorial por parte dos clientes do professor San Tiago Dantas, a peça advocatícia fez-se acompanhar de parecer do mestre italiano como se lê na publicação do referido memorial, datado de 1952.

A doutrina dos direitos da personalidade foi estudada e divulgada entre nós por Pontes de Miranda, Orlando Gomes e Rubens Limongi França há mais de três decênios, porém, San Tiago Dantas, em seu programa de Direito Civil, em parte geral, no capítulo XIV intitulado A Personalidade, de 1942, dedica ao assunto nove páginas, onde examina alguns de seus tipos inclusive referindo-se aos direitos de autor. Desenvolve a matéria tratando-a em subtítulos como a dogmática dos direitos da personalidade, características dos direitos da personalidade, sanção civil e classificação dos direitos da personalidade, o que comprova incontestavelmente seu

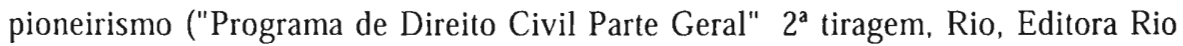
1979, pp. 191 a 200).

Refere-se ao direito à imagem sustentando que a lesão "jamais convalesça, o direito de reclamar não mais prescreve. Será sempre possivel reclamar-se a reintegração do direito, bastando para isso que perdure o estado lesivo" (ob. cit., p. 195).

Em referida obra, na p. 262, usa a expressão negócio ao asseverar: Não há dúvida de que é fato jurídico, pois que todos os atos lícitos o são, mas não é um negócio no sentido preciso da expressão, em que a vontade é a grande causa eficiente (...)"

No volume dedicado ao Direito das Coisas "Programa de Direito Civil III" dedica o capítulo XXVI a Propriedade dos bens imateriais, distinguindo os direitos de autor de caráter patrimonial dos de caráter não-patrimonial.

Aborda o aspecto histórico ressaltando que "na Alemanha, só no século XIX veio a ser conhecido o direito de autor" (Rio, Editora Rio, 1979, pp. 304 a 307) e desenvolve a natureza jurídica de direitos da personalidade para o Direito de Autor com fundamento nas idéias de Gierke e a natureza de direito patrimonial de autor na visão de Kohler admitindo, contudo, os direitos de natureza patrimonial 
(pp. 310, 311 e 312).

É necessário apontar que os três volumes do Programa de Direito Civil" resultam de apostilas obtidas de notas taquigráficas das aulas ministradas entre 1940 e 1945. A reunião em forma de livro documenta a anterioridade cronológica em relação aos cursos editados posteriormente.

É útil relembrar a falta de manuais ou cursos de Direito Civil, o que levou o editor Saraiva a publicar, em 1934, as "Instituições de Direito Civil" de Roberto de Ruggiero, em três volumes, reproduzindo a tradução portuguesa do Visconde Ary dos Santos.

$\mathrm{Na}$ atividade como internacionalista deve ser citado o parecer datado de 20 de setembro de 1944 sobre "Responsabilidade dos negociadores de tratados" concernente a atuação do ministro das Relações Exteriores do Equador por ter assinado o Protocolo do Rio de Janeiro que veio a pôr termo à questão secular de limites entre o Peru e o Equador. O texto está publicado no Boletim da Sociedade Brasileira de Direito Internacional, n. 3, janeiro-junho de 1946, pp. 160-164.

Há outros importantes pareceres elaborados como membro da Comissão Interamericana de Jurisconsultos, da Organização dos Estados Americanos, OEA.

A atuação como ministro das Relações Exteriores está documentada no livro Política Externa Independente publicado em 1962, pela Editora Civilização Brasileira S.A. No prefácio San Tiago Dantas esclarece: A política exterior independente, que encontrei iniciada no Itamarati e procurei desenvolver $e$ sistematizar, não foi concebida como doutrina ou projetada como plano antes de ser vertida para a realidade. Os fatos precederam as idéias. As atitudes, depois de assumidas em face de situações concretas que se deparam à Chancelaria, patentearam uma coerência interna, que permitiu a sua unificação em torno de um pensamento central de governo" (p. 5).

Os lineamentos da política exterior do Brasil constam do discurso proferido pelo chanceler San Tiago Dantas na VIII Reunião de ministros das Relações Exteriores, realizada a 24 de janeiro de 1962, publicado na Revista Brasileira da Política Internacional (ano V. março de 1962, n. 17. pp. 117 a 127).

San Tiago Dantas contribuiu com grande talento para que as novas gerações pudessem reverenciar a obra de grandes juristas, o que concretizou no livro Figuras do Direito" (Rio de Janeiro, Livraria José Olympio Editora 1962). Trata-se de estudos produzidos até o advento da atividade parlamentar. 
A respeito desta a Câmara dos Deputados editou volume com seus principais trabalhos e discursos parlamentares, os quais impressionavam porque quando não foi escrito, mas taquigrafado, nada havia a retocar.

Os estudos que o compõem "Figuras de Direito" são: "Cairu Protagonista de sua Época" "Rui Barbosa e a Renovação da Sociedade" "Rui Barbosa e o Código Civil" "Ciência e Consciência Um Estudo sobre Clóvis Bevilacqua" "Lacerda de Almeida Arcaísmo e Modernismo" "Judicatura e Personalidade - Saudação a Narcélio de Queiroz" "Um Republicano Centenário de Lúcio de Mendonça" "Francisco Campos Logos e Pragma" "Pires e Albuquerque e o Ministério Público" e "Um Mestre Autêntico Matos Peixoto"

Foi um amigo dileto do mestre San Tiago Dantas, o professor Marcílio Marques Moreira, quem sintetizou a função renovadora que o grande intelectual atribuía ao Direito: "Não foi por acaso, que seu maior pendor profissional se inclinou pelo Direito Civil, campo por excelência dos progressos aluvionais, e não dos saltos revolucionários. Sua postura sempre foi a de um reformista que via na inovação, vigorosa mas gradual, a melhor garantia para a segurança das instituições e compreendia que a solução negociada dentro da processualística legal era a mais firme garantia para viabilizar as reformas de base que considerava indispensáveis" ("De Maquiavel a San Tiago" Brasília, Editora Universidade de Brasília, 1981, p. 80).

Ainda: 'Professor de um novo humanismo pedagógico, em que cada indivíduo é visto como protagonista de sua época. como veículo de soluções comuns reclamadas pela coletividade, soluções em que se harmonizam o permanente e o circunstancial, a essência e a existência" (ob. cit., p. 81).

Augusto Frederico Schmidt assim o analisou: "preparou-se, também, Dantas, longamente, para a conquista do poder. Desde a adolescência estudou, afiou a espada, utilizou a poderosa máquina de compreender de que era dotado; ... San Tiago nasceu para classificar e clarificar as coisas, distingui-las, nomeá-las, retirá-las da obscuridade, fazê-las acessiveis ao entendimento sem, no entanto, vulgarizá-las conservando-lhes a elegância necessária graças a uma formulação correta, simples" (em Prefácio a "Dom Quixote Um apólogo da alma ocidental" de San Tiago Dantas, $2^{\mathrm{a}}$ ed., revista, Rio, Tempo Brasileiro, 1964).

Afonso Arinos de Melo Franco: "O intelectualismo de San Tiago, fosse ele literário, jurídico ou político, não era artificial, mas instrumental. Certos espíritos captam o real pelo sensivel, intuitivamente; outros, fortes mas rombudos, 
devastam a realidade quando supõem apresá-la pela força; finalmente alguns, e, entre estes, conspícuamente, o de San Tiago, só são capazes de penetrar a realidade com o agudo estilete do raciocínio. Não que ele, San Tiago, fosse insensivel. Ao contrário, sensivel era, e muito. Mas, nele, a sensibilidade só funcionava no campo afetivo; nunca influía na conduta, cuja pauta só era marcada pelas notas da inteligência. Verifiquei, aos poucos, que isto lhe era inerente e, pois, nada tinha de artificial" (em Prefácio a "Dom Quixote Um apólogo da alma ocidental" ob. cit., p. XVIII).

\section{Direito agrário}

"Pode-se suceder que a relação de equilibrio entre os problemas e os meios de controle se rompa por uma perda dos controles tecnológicos ou por uma perda dos controles ético-sociais. No primeiro caso, a sociedade sucumbe pela incapacidade de sua classe dirigente de conservar, de adquirir ou de inventar as técnicas reclamadas por problemas do meio físico, como o das secas e deserto, o das endemias e epidemias, ou reclamadas por problemas do meio físico, como o das terras cansadas, o da diminuição da fertilidade, o das secas e desertos (...)" ("Palavras de um Professor" $1^{\mathrm{a}}$ ed., Rio, Forense, 1975, p. 76).

No estudo "Humanismo e Direito" aula proferida no curso sobre tal tema organizado pela Pontifícia Universidade Católica do Rio de Janeiro, em 1948, após se referir a Juízo de valor, a elementos metajurídicos, a diferenciação de tratamento que pode ocorrer nas "normas jurídicas que determinam os deveres $e$ direitos dos individuos, que limitam ou protegem sua atividade, muitas vezes se introduzem distinções e diferenciações, que criam para certas classes ou gêneros de indivíduos um tratamento mais rigoroso ou mais benéfico que o dos demais" ("Palavras de um Professor" ob. cit., p. 125), após indagar de onde provém o critério diferenciador e indicar o princípio da proporcionalidade aponta que outras vezes " a diferenciação deriva de uma razão metajurídica"

E explica o porquê: "Não é para corrigir através de uma dosagem de proteção jurídica a desigualdade natural, que o legislador introduz dissimetras, mas pelo fato de dar diferente valor aos individuos, ou porque nos pertençam e outros não pertençam ao grupo nacional" o que por outras razões que indica como "exemplo corrente, verificado a cada passo nas legislações democráticas, as formas concedidas a nacionais, como o usucapião pro-labore (...)" (ob. cit., pp. 125 e 126). 
Para encerrar: senhores acadêmicos, falar-vos de San Tiago Dantas tem o objetivo não apenas de vos ilustrar a respeito de legado jurídico de tão-rica personalidade, mas, também, vos dar uma opção para um modelo que, em verdade, cada um de nós, sempre, deve ter e tem.

São Paulo, dezembro de 1995. Recomposta pelo Serviço Técnico de Imprensa, com autorização do Autor, em junho de 2000. 


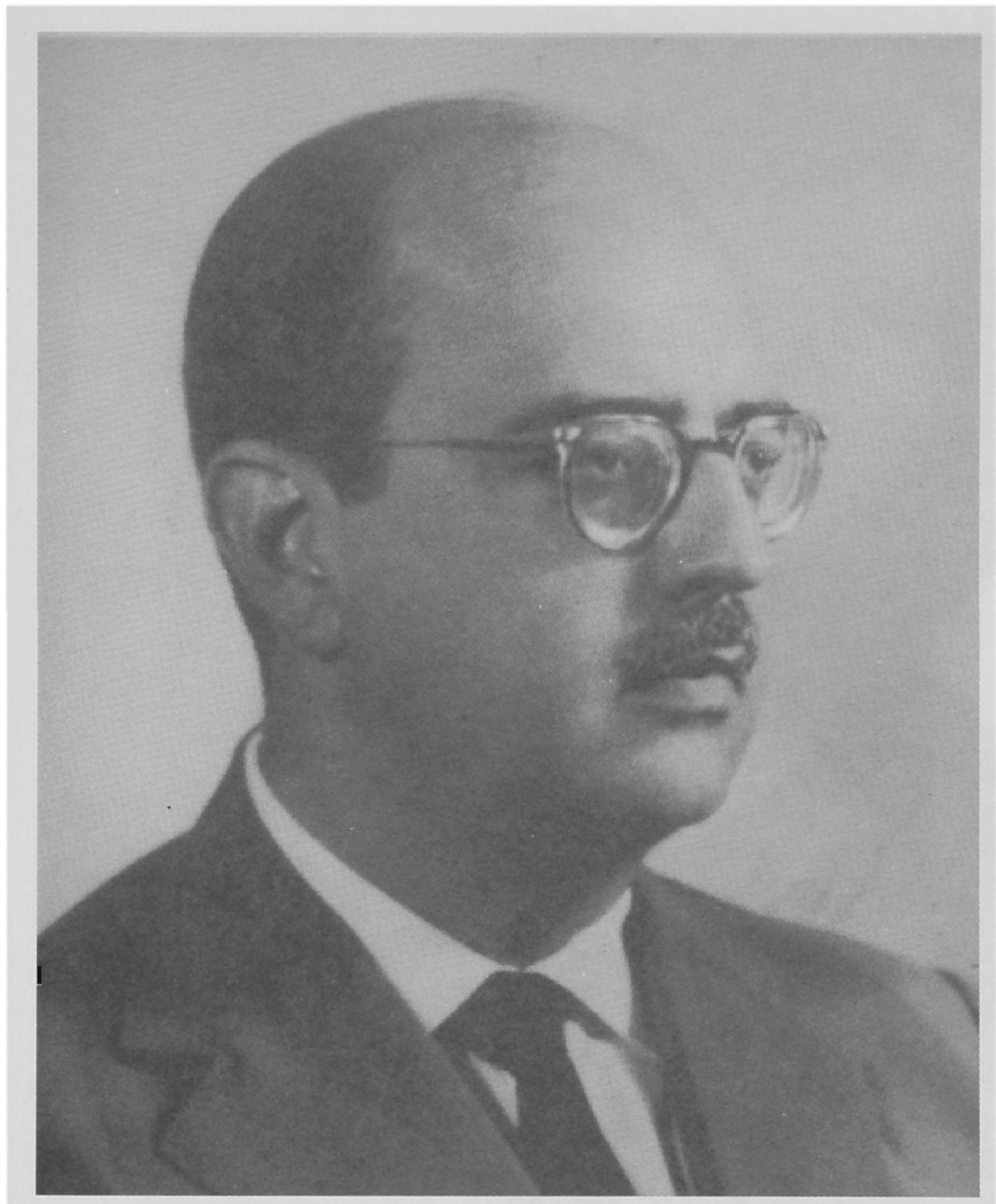

Professor Doutor Francisco Clementino de San Tiago Dantas 